\title{
Tam Sayılı Doğrusal Programlama ile Araba Terminallerinde Kapasite Analizi: Bir ArabaTerminalinde Uygulama
}

\author{
Güldem Elmas ${ }^{1 *}$ \\ 1* İstanbul Üniversitesi-Cerrahpaşa, Mühendislik Fakültesi, Deniz Ulaştırma İşletme Mühendisliği, İstanbul, Türkiye, (ORCID: 0000-0002-2585-9650), \\ gelmas@istanbul.edu.tr
}

(İlk Geliş Tarihi 30 Ocak 2021 ve Kabul Tarihi 28 Mart 2021)

(DOI: $10.31590 /$ ejosat.871295)

ATIF/REFERENCE: Elmas, G., (2021) Tam Sayılı Doğrusal Programlama ile Araba Terminallerinde Kapasite Analizi: Bir Araba Terminalinde Uygulama. Xxxx Xxxx Xxxx. Avrupa Bilim ve Teknoloji Dergisi, (23), 322-329.

Öz

Otomotiv fabrikaları iç lojistik süreçlerde sağladıkları optimizasyonu, dış lojistik süreçlerde de sağlamak istemektedirler. Otomotiv sektöründe, limanlarda yaşanan sıkışıklık, limanlardaki yetersiz kapasiteler, gemi gecikmeleri, gemilerin limanlar için ayırdıkları düşük kapasiteler, ana taşıma modu denizyolunda yaşanan en büyük sorunlar olarak yer almaktadır. Araba terminallerinin kapasitelerinin ihracat-ithalat rakamlarına uyumlu olacak şekilde düzenlenmesi gerekmektedir. Uygulama çalışmasının yapıldığı araba terminali, araba ihracat ve ithalatının yoğun olarak yapıldığı ülkemiz limanlarından biridir. Araba Gemilerinin limanlara yaptıkları sefer sayısı çok önemli bir faktördür. Akış ihracat araçları için firmadan araç park sahasına, araç park sahasından gemiye şeklinde olmaktadır. İthal araçlar için ise akış gemiden araç park sahasına oradan da firmalara olacak şekildedir. Bu çift taraflı akış göz önünde bulundurularak kurulan tam sayılı doğrusal programlama modelinde kapasite analizi problemi, limandaki kapasite kısıtları dikkate alınarak ve yüklenen ihracat araçlarının en büyüklenmesi yapılarak ele alınmıştır. Kurulan matematiksel model GAMS yazılımı CPLEX çözücüsü kullanılarak çözülmüştür. Mevcut kapasite ile beraber, aylık gelen gemi sayısı, gemi kapasitesi, araç park sahası kapasiteleri arttırılarak model tekrar tekrar çözülmüştür. Amaç, kısıtların değiştirilmesi ile araç terminalinin en verimli şekilde kullanılmasını sağlamaktır.

Anahtar Kelimeler: Araç Terminali, Tam Sayılı Doğrusal Programlama, Kapasite Analizi, Otomotiv Lojistiği

\section{Capacity Analysis with Integer Linear Programming: Application in a Auto Terminal}

\begin{abstract}
Automotive factories aim to provide the optimization not only in internal logistics processes but also in external logistics processes. In the automotive sector, congestion in ports, insufficient capacities at ports, ship delays, low capacities reserved by ships for ports, can be considered the crucial problems experienced in maritime transport. The capacities of car terminals should be arranged in relation with line with export-import outcomes. The car terminal, where the implementation work is carried out, is one of the main port of our country where car exports and imports are made intensely. The number of voyages made by Pure Car Carriers to ports is a very important factor. For export vehicles, the flow is from the company to the vehicle parking area, from the vehicle parking area to the ship. The transportation flow of the exported cars should be applied as carrying from the factory to vehicle parking area and then transfer to the ships. On the other hand the imported cars should be transferred from the ships to vehicle area and they must be moved to compaines. In the integer linear programming model established by considering this double-sided flow, the problem of capacity analysis was addressed by taking the capacity constraints at the port and maximizing the loaded export vehicles into account. This established mathematical model was solved using GAMS software CPLEX solver. Along with the current capacity, the model has been solved over and over again by increasing the monthly incoming ships, vessel capacity, and vehicle parking area capacities. The purpose of this model is to change the constraints and to ensure the most efficient use of the vehicle terminal.
\end{abstract}

Keywords: Auto Terminal, Integer Linear Programming, Capacity Analysis, Automotive Logistics.

*Sorumlu Yazar: gelmas@istanbul.edu.tr 


\section{Giriş}

Ülkemizin en önemli ihracat kalemlerinden biri olan otomativ sektörü her geçen gün üretim ve ihracat kapasitesini daha da arttırmaktadır Otomativ sektörü çok büyük bir dağıtım zincirine sahiptir. Dağıtım zincirini oluşturan tüm halkaların en düzgün şekilde çalışması gerekmektedir. (Elmas, 2011) Ülkemizin otomotiv sektöründeki rekabet gücü ancak bu şekilde arttırılabilecektir. Zaman, kapasite ve kalite problemleri müşteri kaybına yol açmaktadır. Otomotiv lojistiğinin doğru planlanması ile daha düşük maliyetler elde edilebilecektir. Böylece rekabet ve gelişim için ortak projeler üretilebilecektir.( Elmas, 2014)

Otomotiv sanayicileri bakımından esas rekabet ana firmalarının diğer ülkelerdeki fabrikaları ile olmaktadır. Bu rekabette fiyat dolayısı ile lojistik maliyetler önemli bir yer tutmaktadır. (Ergin 2011) Üretimi ülkemize kazandırılan markalar için lojistik rekabet edebilirliğimiz önemli bir unsur olarak belirlenmektedir. Bunun aksi durumlarda model üretimlerinin rakip fabrikalara gitmesi kaçınılmaz olmaktadır. $\mathrm{Bu}$ esastan düşündügümüzde lojistik oyuncuları ile işbirliğinin önemi çok ciddi boyutlara ulaşmaktadır. (Elmas,2011)

Otomotiv sektörünün hedefleri arasında dış lojistik süreçlerinden olan taşıma, liman, gümrükleme gibi aşamaların optimizasyonunu sağlamaktır. Limanlardaki yetersiz kapasite, gemi gecikmelerinden kaynaklanan senkronizasyon problemi ciddi sorunlar oluşturmaktadır. (Ergin and Eker, 2019). Bu sıkıntılar hem depolamada hem de stevedoring hizmetlerinde ciddi aksamalara ve maliyet artışlarına yol açmaktadır. $\mathrm{Bu}$ durumda takip eden işlerde de aksamalar ve darboğazlar oluşmaktadır. Gemi taşımacılığı zincirin en zayıf halkası konumuna doğru gitmektedir.(Elmas, 2011)

Araba Terminallerinde yüklenen/boşaltılan gemilerin periyodik ziyaretlerle servis verdiği ve kara tarafındaki alıcıların talep ettikleri hizmet göz önüne alındığında, araba terminallerinin depolama kapasitesi çok önemli bir sorun arz etmektedir. Dolayısıyla araba terminallerinin, yükleme boşaltma için terminale yanaşan gemilerin kapasitelerinin çok değişken oluşuna ve kara tarafı taşımacılık şekillerine ayak uydurabiliyor olması gerekmektedir. Araba terminallerindeki etkin kapasite kullanımı çok önemli bir konu olarak ortaya çıkmaktadır. (Büyüközer 2006)

Literatürde, otomotiv lojistiğinde araba terminallerinin önemini, Dias ve arkadaşları (2010), Holweg ve Miemcyzk (2003) yaptıkları çalışmalarda vurgulamışlardır. Mattfeld ve Kopfer (2003) çalışmalarında araba terminallerinde gerçekleştirilen terminal operasyonlarından araçların gemiye aktarılması probleminin optimum düzeyde planlanmasını modellemişlerdir.

Gamberdalla ve arkadaşları (1998) çalışmalarında, örnek olay çalışması yaparak, Akdeniz'de yer alan Contship La Spezia Konteyner Terminal'inin kapasite analizini tam sayılı doğrusal programlama yöntemini kullanarak yapmışlardır. Beskovnik ve Twrdy (2010) tarafından yapılan çalışmada konteyner terminallerinde gerçekleşen tüm operasyonların optimize edilerek terminal planlaması yapmışlardır. Pau ve arkadaşları (2005) tarafından yapılan çalışmada ilerleyen günlerde limanlarda sayı olarak artacak olan araba gemilerinin terminallerde trafik artışına neden olacağı öngörülmektedir. Bu nedenle trafik artışı ile başa çıkabilmek için terminal yöneticileri terminal operasyonlarında bir değişiklik, genişleme veya verilen hizmet düzeyi göz önünde alındığında yeni bir terminal inşaatının gerekli olup olmadığına karar verdikleri belirtilmektedir.

Literatürde daha sıklık ile Ro-Ro terminalleri ile ilgili çalışmalar görülmektedir. Ro-Ro terminallerinde kapasite analizi kapsamında, Mangan ve arkadaşlarının (2002) çalışmasında araçların araç terminallerindeki hareketlerinin ve depolanmalarının optimizasyonu modellenmiştir. Özkan ve arkadaşları (2016) yaptıkları çalışmada Simülasyon modelleme yöntemi ile oluşturulan senaryolar ile üç değişkenin “ Terminallere gelen kamyon sayısı", "Terminaller arası mesafe ", ve " Ro-Ro gemi kapasitesi" nin Ro-Ro terminal kapasitesine olan etkilerini belirlemişlerdir. Sonuçlar, terminal kapasitesini en çok etkileyen değişkenin 'terminallere gelen kamyon sayısı' olduğunu göstermektedir.

Cordeau ve arkadaşları (2011) çalıșmalarında araba terminalinde tamsayılı programlama ile operasyon süresinin minimizasyonunu hedeflemiştir. Roll-on / roll-off (Ro-Ro) taşımacılığı, ticari araçların büyük ölçekli aktarımı için verimli ve rekabetçi bir yöntemdir. Ancak, Ro-Ro terminallerinin düşük verimli operasyonları ve yetersiz depolama kaynakları, Ro-Ro taşımacılığının gelişimini sınırlandırmıştır. Chen ve arkadaşları (2021) çalışmalarında arabaların sahaya gelmesi için depolama yeri belirleme problemini araştırmış, gemi yükleme verimliliğini artırmayı ve Ro-Ro terminallerinde verimli depolamaya katkıda bulunmayı amaçlamıştır. Iannone ve arkadaşları (2016) Ro-Ro terminallerindeki operasyonları tanımlamışlar, operayon kararlarını analiz edip termnal süreçlerinde yer alan maliyetlerin lojisik maliyetler üzerindeki etkisini araştırmışlardır.

Yalçıner ve Can (2019) Tam sayılı programlama tekniği kullanarak raf alanı optimizasyonu gerçekleştirmişlerdir. Şahin ve arkadaşlarının (2020) yaptığı çalışmada bir makine fabrikasında yarı mamul depolama sistemi için etkin raf alanı yerleşimi problemi için tam sayılı matematiksel modellerden yararlanmışlardır.

\section{Materyal ve Metot}

Çalışma, yapılan gözlemler sonucunda limanda darboğaz oluşturduğu tespit edilen araba terminalinde gerçekleştirilmiştir. Limanın bulunmuş olduğu hinterlantta ülkemizin en büyük otomobil fabrikaları bulunmaktadır. Liman içersinde yer alan araba terminali kapasitesini etkin kullanamadığı için fabrikaların taleplerine karşılık verememektedir. Araba Terminalinin kapasite sorunu yüzünden sevkiyatını yapamadığı araçlar fabrikadan daha uzak illerdeki limanlara sevk edilmektedir. Bu durum lojistik maliyetlerin artmasina neden olmaktadır.

Araba terminalinin araç park sahasında meydana gelen çift taraflı akış gözününde bulundurularak kurulan tam sayılı doğrusal programlama modelinde kapasite analizi problemi, limandaki kapasite kısıtları dikkate alınarak ve yüklenen araçların en büyüklenmesi yapılarak ele alınmıştır. Kurulan matematiksel model GAMS yazılımı CPLEX çözücüsü kullanılarak çözülmüştür. Mevcut durum ile beraber, aylık gelen gemi sayısı, gemi kapasitesi, araç park sahası kapasitesi arttırılarak oluşturulan seneryolar çözdürülmüştür. Neticesinde elde edilen sonuçlar yorumlanmıştır.

\subsection{Tam Sayılı Doğrusal Programlama}

Çalışma kapsamında ele alınan Araba Terminalinin bulunduğu limanda kapasiteyi etkileyen tüm kısıtlar ortaya konmuştur.. Çalışma kapsamında incelenen problemin çözümüne yönelik olarak Tam Sayılı Doğrusal Programlama Modeli geliştirilmiştir. 
Model kapasite analizi ile sınırlı değildir. Ayrıca araçların gemilere yüklenme tarihini belirleyen bir program belirler.

\subsection{Araba Terminalindeki Mevcut Durum}

İthal araçlar belirli aralıklar ile büyük partiler halinde araç park sahasına ulaşmaktadırlar. İthalatçı firmalar belli bir süre araç park sahasında bekleyen araçları teslim almaktadırlar.İhrac olacak olan araçlar için düzenleme ters yönde çalışmaktadır.
Belirli bir tarihte gemiye yüklenecek ihracat araçları fabrikalar tarafindan limandaki depo süresi boyunca araç park sahasında yer kaplamaktadırlar. İthal araçları getiren gemi, araç park alanı ve araç park alanı akışları tanımlanmaktadır. İhraç araçlar için önce fabrikalar araçları araç park alanına getirmektedir. Ardından araçlar gemilye yüklenmektedir. Araç park sahası kapasitesi 5500 araçtır. Araba Terminalindeki Akış Şekil 1'de gösterilmektedir.

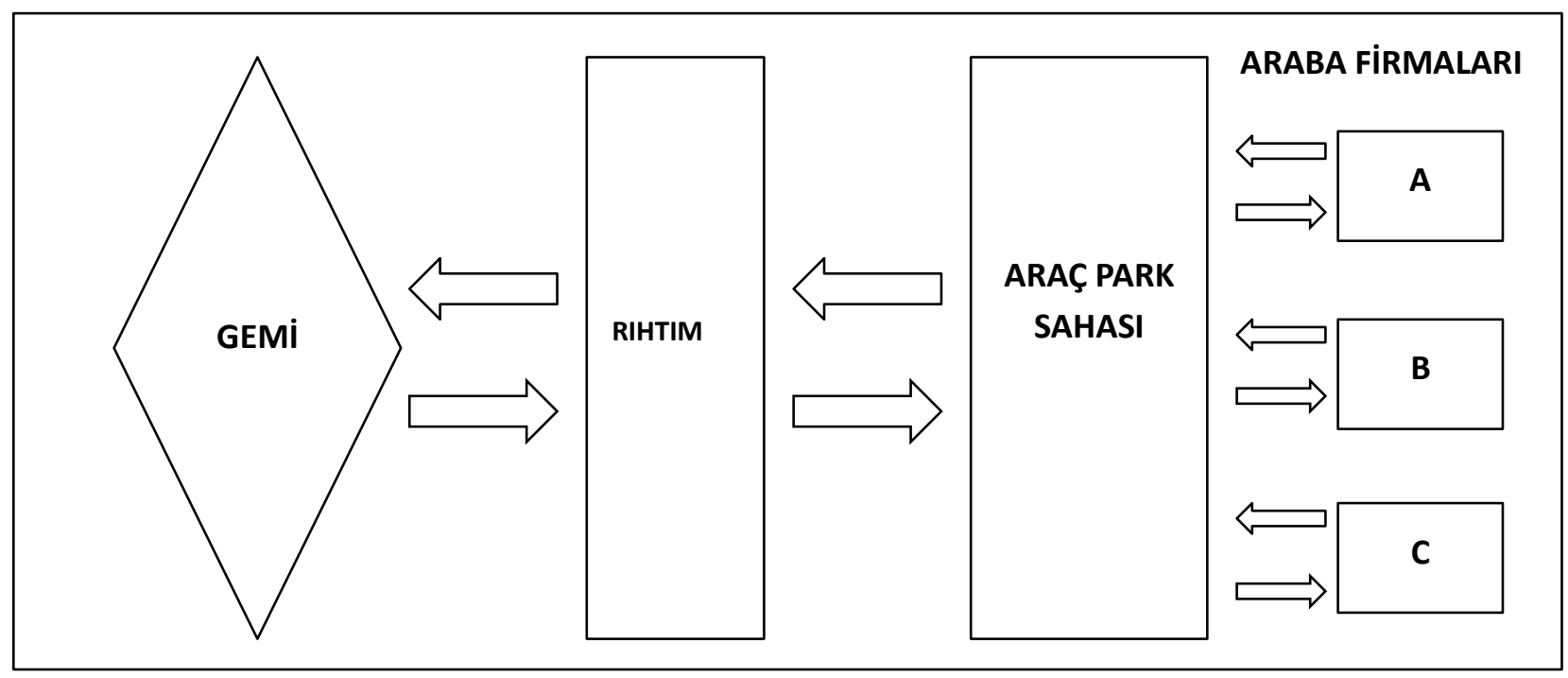

Şekil 1: Araba Terminalindeki Akış

\subsubsection{Varsayımlar}

a) Planlama peryodu 12 ay olarak belirlenmektedir ve dönem başlangıcı 1 Ocak olarak kabul edilmektedir.

b) Üreticiden terminale teslim edilen araç sayısı için bir üst ve alt sinır kullanılmaktadır.

c) Araç park sahasında bir önceki planlama peryodundan 1000 araç kalmış olduğu kabul edilmektedir.

d) Önceki yükleme planından kalan ithal araç yoktur.

e) İthal araç sayısı, geminin kapasitesine göre önemsizdir. Bu nedenle, aylık ithalat tahmini her seferinde karşılanmaktadır.

f) 1 yilda gerçekleştirilen yükleme boşaltma süreleri için ortalama bir değer bulunmaktadır. Bu değer hem yükleme hem de boşaltma için 5 dakikadır.

g) Limana gelen ithal araçların limanda kalma sürelerinin sabit oranda azaldığı ve 5 günde tamamının gönderilmiş olduğu kabul edilmektedir.

h) İthal ve ihraç araçların gönderilebilmesi için bir gün önceden araç park sahasına yerleştirilmiş olması gerekmektedir.

i) Gemi kapasiteleri bilinmektedir.

j) Şekil 1'de görüldüğü gibi rıhtum ile araç park alanı arasında bir akış vardır. Bu sistemde rıhtım bir aktarma düğümü olduğundan, rıhtım dikkate alınmaz.

\subsubsection{Modele İlişkin İndisler ve Parametreler}

Modele ilişkin tanımlarda bazı simge ve indislerden yararlanılmaktadır.

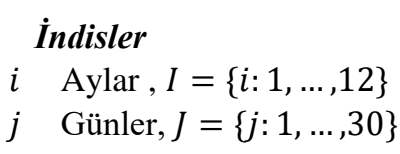

\section{Parametreler}

$D_{i}^{\text {exp }} \quad i^{\text {th }}$ ayda ihracatı yapılacak olan araç sayısı

$D_{i}^{i m} \quad i^{\text {th }}$ ayda ithalatı yapılacak olan araç sayısı.

$S_{i} \quad i^{\text {th }}$ ayda kullanabileceği gemi sayısı için üst limit $s_{i}=16 \quad i \in I$.

$C^{V P A} \quad$ Araç park sahası kapasitesi , $C^{V P A}=100$ araç.

$T$ Araçların yüklenmesi için üst sınır, $T=1440$ dakika

$C^{S}$ Gemi kapasitesi, $C^{S}=2000$ araç

$\theta$ Operasyon süresince çıkan atıl zaman, $\theta=60$ dakika

$L \quad$ Firmalardan 1 günde gelebilecek araç sayısı için alt limit , $U=200$ araç/gün.

$U$ Firmalardan 1 günde gelebilecek araç sayısı için üst limit, $U=1300$ araç/gün. 
$Q \quad$ Bir önceki planlama peryodundan kaldığı kabul edilen araç sayısı $Q=1000$ araç

\section{5 dakika/araç}

$\varphi$ Bir aracın gemiden yükleme boşaltma süresi , $\varphi=$

$\alpha$ İthal edilen araçlar $\alpha$ günde araç park alanından transfer edilir.

\subsubsection{Karar Değişkenleri}

Tam sayılı doğrusal programlama modelinde ayın belirli günlerinde gemiye yüklenecek, gemiden inecek, araç park sahasında bekleyecek olan araç sayılarını belirlemek hedeflenmiştir. Aşağıda karar değişkenleri yer almaktadır.

\section{$\underline{\text { Tam Savılı Değiskenler }}$}

$x_{i j} i^{\text {th }}$ ayda $j^{\text {th }}$ günde gemiye yüklenecek (ihracat )

araç sayıs1

$$
z_{i j} i^{\text {th }} \text { ayda } j^{\text {th }} \text { günde gemiden boşaltılacak (ithal) }
$$

araç sayısı

$v_{i j} i^{\text {th }}$ ayda $j^{\text {th }}$ günde fabrikadan araç park sahasına gelecek araç sayısı

\section{İkili (Binarv) Değiskenler}

$y_{i j}= \begin{cases}1 & i^{t h} \text { ayda } j^{t h} \\ 0 & \text { aksi halde }\end{cases}$

$\pi_{i j}= \begin{cases}1 & i^{t h} \text { ayda } j^{t h} \text { günde araç park sahasına araç gelirse } \\ 0 & \text { aksi halde }\end{cases}$

\section{$\underline{\text { Negatif olmavan Değiskenler }}$}

$t_{i j} i^{\text {th }}$ ayda $j^{\text {th }}$ günde gönderilmeye hazır araç sayısı

$\mu_{i j} i^{\text {th }}$ ayda $j^{\text {th }}$ günde geminin yükleme boşaltma

$$
h_{i j} i^{\text {th }} \text { ayda } j^{\text {th }} \text { günde ihracat araçlarının }
$$

yüklenmesinden sonra gemideki atıl kapasite

$f_{i j} i^{\text {th }}$ ayda $j^{\text {th }}$ günde ithalattan kalan araçların toplam sayıs 1

\subsubsection{Modelin Formüle Edilmesi}

$\mathrm{Bu}$ bölümde problemin kısıtları ifade edilmektedir. Çalışmada ele aldığımız Araba terminalinde işleyen sistemden ötürü bazı kısıtlar bulunmaktadır. Modelde amaç Araba Terminalinde yüklenecek ihracat araç saysının en büyüklenmesidir.

Araba Terminalinin mevcut kapasitesi talebi karşılayamadığından ihracat araçlarını maksimize etmek anlamlı olmaktadır.Araç park alanı kapasitesi $C^{V P A}$ olarak tanımlanmaktadır. Planlanan operasyon günü için toplam ihraç ve ithal edilen araç sasyısı araç park alanı kapasitesini $\left(C^{V P A}\right)$ aşmamaktadır.

Herhangi bir gemi 1 günden fazla kalamaz. Operasyonların toplam süresi (araçların gemiden indirilmesi-araçların gemiye yüklenmesi) olarak belirlenen 24 saat kısıtı çok ağır bir kısıt olduğu için diğer kısıtlar gereksiz kısıtlar haline gelmektedir. $\mathrm{Bu}$ yüzden 24 saat kısıtı gevşetilerek üst sınır 1600 dakikaya çıkartılmaktadır. Amaç fonksiyonu aynı zamanda ihraç araç sayısını maksimum yaparken gelen gemi sayısını da limandaki trafiği azaltmak ve operasyon maliyetlerini düşürmek amacıyla minimum yapmaktadır.

Bunu sağlayabilmek için amaç fonksiyonuna gemideki atıl kapasiteyi minimum etmesini sağlayacak bir kısım eklenmektedir. Amaç fonksiyonunun matematiksek gösterimi aşağıdaki gibidir (1).

süresi

$$
\max \sum_{i \in I} \sum_{j \in J} x_{i j}+\sum_{i \in I} \sum_{j \in J} \frac{T-\mu_{i j}}{\varphi}+\sum_{i \in I} \sum_{j \in J}\left(h_{i j}-C^{S}\right)
$$

Amaç fonksiyonu aynı anda 3 kriteri birden barındırmaktadır (1). İlk kısım (2)'de verilmektedir. İhraç edilen araç sayısının en büyüklenmesidir.

$$
\sum_{i \in I} \sum_{j \in J} x_{i j}
$$

Amaç fonksiyonunda 2. kısım (3)’te verilmektedir. Sonucun T’yi aşamayacağını ifade etmektedir. Süreyi $\varphi$ bölerek araç sayısına çevirmektedir 


$$
\sum_{i \in I} \sum_{j \in J} \frac{T-\mu_{i j}}{\varphi}
$$

Amaç fonksiyonunun 3. Kısmı (4)’te verilmektedir. Gemideki atıl kapasite en küçüklenmesidir.

$$
\sum_{i \in I} \sum_{j \in J}\left(h_{i j}-C^{S}\right)
$$

Kısıtların matematiksel gösterimi aşağıdaki gibidir.

Kısıt (5), toplam ihraç edilen araç sayısııın ihracat tahmininden az veya eşit olmasını sağlamaktadır.

$$
\sum_{j \in J} x_{i j} \leq D_{i}^{e x p} \quad \forall i \in I
$$

Kısıt (6), ithal gelen araç sayısı o ayki ithalat tahmini kadar olmaktadır.

$$
\sum_{j \in J} z_{i j} \leq D_{i}^{i m} \quad \forall i \in I
$$

Kısıt (7), ithal araçları araç park sahasına ihraç araçları gemiye yüklemek için geçen süreyi belirlemektedir.

$$
\mu_{i j} \geq \varphi\left(x_{i j}+z_{i j}\right)+\theta \quad \forall i \in I, j \in J
$$

Modelin çalışabilmesi için Toplam operasyon süresinin. $T^{\prime}=1600$ dakikaya yükseletilmesi gerekmektedir.

$$
\mu_{i j} \leq T^{\prime} \quad \forall i \in I, j \in J
$$

Kısıt (9) 1 ay içinde terminale gelen gemi sayısının üst sınırını belirlemektedir.

$$
\sum_{j \in J} y_{i j} \leq S_{i} \quad \forall i \in I
$$

Kısıt (10) Eğer gemi gelmişse $\left(y_{i j}=1\right) x_{i j} \leq C^{S}$ aksi takdirde $x_{i j}=0$.

$$
x_{i j} \leq C^{S} \cdot y_{i j} \quad \forall i \in I, j \in J
$$

Kısıt (11) Geminin terminale gelmesi durumunda ithal araç boşaltılmaktadır. Gemi gelmediyse ithal araç da gelmemektedir.

$z_{i j} \leq C^{S}$ gemi gelirse $\left(y_{i j}=1\right)$, aksi takdirde $z_{i j}=0$.

$$
z_{i j} \leq C^{S} \cdot y_{i j} \quad \forall i \in I, j \in J
$$

Kısıt (12), (13) ve (14) İhraç edilecek araç saysını belirlemektedir. Kısıt (14), $|J|, J$ kümesinin eleman sayısını ifade etmektedir.

$$
\begin{gathered}
t_{11}=Q-x_{11}+v_{11} \quad \forall i \in I, j \in J \\
t_{i j}=t_{i, j-1}-x_{i j}+v_{i j} \quad \forall i \in I, j \in J \text { and } j \geq 2 \\
t_{i j}=t_{i-1,|J|}-x_{i j}+v_{i j} \quad \forall i \in I, j \in J \text { and } i \geq 2
\end{gathered}
$$

İthal araç sayısının doğrusal olarak azaldığı $\alpha$ günde bittiği kabul edilmektedir. (15) ve (16)'da , Araç park sahasında kalan ithal araç sayısı hesaplanmaktadır. 


$$
\begin{gathered}
f_{i j} \geq \sum_{k=|J|-\alpha+j+1}^{|J|}\left(\frac{\alpha-(j+|J|-k)}{\alpha} \cdot z_{i-1, k)}\right)+\sum_{k=1}^{j}\left(\frac{\alpha-(j-k)}{\alpha} \cdot z_{i k}\right) \forall i \in I, j \in J \text { and } \mathrm{i} \geq 2, j \\
\leq \alpha-1 \\
f_{i j} \geq \sum_{k=j-(\alpha-1)}^{j}\left(\frac{\alpha-(j-k)}{\alpha} \cdot z_{i k}\right) \forall i \in I, j \in J \text { and } j \geq \alpha
\end{gathered}
$$

Kısıt (17) Araç park alanındaki toplam araç saysının $C^{V P A}$ değerinden az veya eşit olmasını sağlamaktadır.

$$
f_{i j}+t_{i j} \leq C^{V P A} \quad \forall i \in I, j \in J
$$

$x_{i j}$ 'in gönderilmeye hazır araç sayısından az veya eşit olduğu durumlardagemiye $x_{i j}$ kadar ihraç araö yüklemek mümkün olmaktadır. Kısıt (18), (19) ve (20) Yüklenen ihraç araç sayısının araç park alanındaki mevcut araç sayısı ile sınırlandırılmasını sağlamaktır.

$$
\begin{gathered}
x_{11} \leq Q \\
x_{i j} \leq t_{i, j-1} \quad \forall i \in I, j \in J \text { ve } j \geq 2 \\
x_{i 1} \leq t_{i-1,|J|} \quad \forall i \in I \text { ve } i \geq 2
\end{gathered}
$$

Kısıt (21) İhracatçının ihracat araçlarını araç park sahasına getirmesi durumunda, teslim edilen miktarın alt ve üst limitler arasında olmasi gerekmektedir.

$$
L \cdot \pi_{i j} \leq v_{i j} \leq U \cdot \pi_{i j} \quad \forall i \in I, j \in J
$$

Kısıt (22) Geminin atıl kapasitesini hesaplamaktadır.

$$
h_{i j}=C^{S} \cdot\left(1-y_{i j}\right)+x_{i j} \quad \forall i \in I, j \in J
$$

\section{Araştırma Sonuçları ve Tartışma}

Oluşturulan model GAMS yazılımı ile çözülmüştür. Liman yönetimi tarafindan beklenen ihracat değeri olan 301.000 araç mevcut kısttlar ile yüklenemeyeceği görülmüştür. Model 162 gemi çağırmış,buna karşılık 299.289 adet araç yükleyebilmiştir.

\subsection{Kurulan Modelin STS Değişimine Göre Analizi}

Gemi kapasitesinin, aylık gelen gemi sayısının ve araç park sahası kapasitesinin attrılması durumunda modelin sonuçlarının nasıl değişeceği tespit edilmiştir.

\subsubsection{Gemi Kapasitesinin Arttırılmasının Modelin Çözümüne Etkisi}

Diğer kısıtlar değiştirilmeden model gemi kapasitesinin 2300, 2400 ve 2500 'e çıkartılması durumlarında tekrar tekrar çözülmüştür. En iyi sonuç gemi kapasitesinin 2300'e çıkartılması durumunda elde edilmiştir. Modelin çözülmesi ile 158 gemi ile 301.182 araç yüklenebileceği sonucuna ulaşılmıştır.

\subsubsection{Aylık Gelen Gemi Sayısının Arttırılmasının Modelin Çözümüne Etkisi}

Diğer kısıtlar değiştirilmeden aylık gelen gemi sayısnın 16'dan sırasıyla arttrrılarak terkar tekrar modelin çözülmesi neticesinde gelen gemi sayısının 20'e çıkarılması durumunda beklenen talebin karşılanacağı görülmüştür. Modelin çözülmesi ile 168 gemi ile 304.200 araç yüklenebileceği sonucuna ulaşılmıştır.

\subsubsection{Araç Park Sahası Kapasitesinin Attırılmasının Modelin Çözümüne Etkisi}

Diğer kısıtlar değiştirilmeden araç park sahası kapasitesi 5500'den 6500'e çıkartılmıştır. Modelin çözülmesi ile 162 gemi ile 299.304 araç yüklenebileceği sonucuna ulaşılmıştır. 


\begin{tabular}{|c|c|c|c|c|}
\hline $\begin{array}{c}\text { Beklenen Talebe } \\
\text { Göre } \\
\text { Değerlendirme }\end{array}$ & $\begin{array}{l}\text { Mevcut } \\
\text { Durum }\end{array}$ & $\begin{array}{c}\text { Gemi } \\
\text { Kapasitesinin } \\
\text { Arttırilmasi }\end{array}$ & $\begin{array}{l}\text { Aylık Gelen Gemi } \\
\text { Sayısının } \\
\text { Arttırılması }\end{array}$ & $\begin{array}{l}\text { Araç Park Sahası } \\
\text { Kapasitesinin } \\
\text { Arttırılması }\end{array}$ \\
\hline $\begin{array}{c}\text { Aylık Gelen Gemi } \\
\text { Sayısı }\end{array}$ & 16 & 16 & 20 & 16 \\
\hline $\begin{array}{c}\text { Araç Park Sahası } \\
\text { Kapasitesi }\end{array}$ & 5500 & 5500 & $\mathbf{5 5 0 0}$ & 6500 \\
\hline Gemi Kapasitesi & 2000 & 2300 & 2000 & 2000 \\
\hline Sonuç & $\begin{array}{c}162 \text { gemi } \\
299.289 \\
\text { araç }\end{array}$ & $\begin{array}{c}158 \text { gemi } \\
301.182 \text { araç }\end{array}$ & $\begin{array}{c}168 \text { gemi } \\
304.200 \text { araç }\end{array}$ & $\begin{array}{c}162 \text { gemi } \\
299.304 \text { araç }\end{array}$ \\
\hline
\end{tabular}

Tablo 1: Modelin sabit sayıların ayrı ayrı değiştirilmesi ile elde edilen sonuçlar

Tablo 1'de GAMS yazılımı ile çözülen modelin sonuçları yer almaktadır.

\section{Sonuç}

Bu çalışmada, modelin çözümü ile ülkemizin en çok araç ihracatının gerçekleştiği limanlardan birinin araba terminalinde, beklenen ihracat ve ithalat rakkamlarına göre elleçleme kapasitenin yeterli olup olmadığının tespit edilmesi amaçlanmıştır. Model de mevcut kısıtlar ile çağırılabilecek gemi sayısı, yüklenebilecek ihracat adetleri, en iyi (optimal) çözümü veren karar değişkenlerinin değerleri hesaplanmıștır. Modelin çözümü sonucunda beklenen ihracat talebinin mevcut kısitlar ile yüklenemeyeceği görülmektedir. Modeldeki sağ taraf sabitleri değiştirilerek sonuçlar tekrar ele alınmıştır. Gemi kapasitesinin, aylık gelen gemi sayısının ve araç park sahası kapasitesinin arttırılması sonucunda modelin sonuçlarının nasıl değişeceği araştırılmıştır. Beklenen talebin karşılanabilmesi için Araba Terminalinin bulunduğu limanın yeni bir yatırım yapıp araç park sahasını arttırması gerekmemektedir. Limanın içinde bulunduğu hinterlanttaki araba fabrikalarının taleplerini karşılayabilmesi için araba taşıyıcı gemilerin limana yaptıkları sefer frekanslarını arttırmak ya da gelen gemilerin araba terminali için ayırdığı kapasitesini arttırmak gerekmektedir. Ayda gelen gemi sayıs1 20 'ye çıkarıldığında ya da araba gemilerinin araba terminali için ayrıdıkları kapasiteyi 2300'e çıkardıklarında araba terminalindeki dar boğaz ortadan kalkmış olacaktır. Çalışma otomotiv terminallerinde kapasite analizini hesaplayabilen genel bir modeldir. Bundan sonra yapılacak çalışmalarda ele alınacak terminallerin özelliklerine göre ilgili kısıtların modele eklenmesi gerekmektedir.

\section{Kaynakça}

Beskovnik, B., \& Twrdy, E., (2010), Planing Organization and Productivity Simulation Tool for Maritime Container Terminals, Transport 2010., 25(3):293-299

Büyüközer, A.(2006). Konteyner Planlaması ve Kapasite Analizi.Y.Lisans, Fen Bilimleri Enstitüsü, İstanbul Teknik Üniversitesi.

Chen, X., Li, F., Jia.B., Wu, J., Gao, Z., Liu, R., (2021), Optimazing storage location assignment in an automotive RoRo Terminal, Transportaion Research Part B 143 (2021), 249-281, https://doi.org/10.1016/j.trb.2020.10.009

Cordeau, F., Laporte, G., Moccia, L., Sorreantino, G., (2011), Optimazing yard assignment in an automotive transshipment terminal, European Journal of Transshipment, 215 (1), 149160, https://doi.org/10.1016/j.ejor.2011.06.008

Dias, Q., Calado,J., \& Mendonça, M., (2010), The Role of European Ro-Ro 4 Port Terminals in The Automotive Supply Chain Management. Transport Geography, 18, 116-12

Elmas,G., (2011), Bursa Bölgesi'nde Otomotiv Lojistiği ve Otomotiv Terminallerinde Kapasite Analizi, Doktora Tezi, İstanbul Üniversitesi, Fen Bilimleri Enstitisü

Elmas, G., (2014) An AHP Model for Choosing Value Creation Factors in Logistics Service for the Logistics Customer, International Conference on Education and Social Sciences, $165-172$

Ergin, A. (2011) Tedarik Zinciri Yönetiminde Konteyner Taşıyıcı Firma Seçimi ve Türkiye'deki Uygulaması, Doktora Tezi, Istanbul Universitesi. 
Ergin, A. \& Eker , I. (2019.) Application of Fuzzy Topsis Model for Container Port Selection Considering Environmental Factors. International Journal of Maritime Engineering, vol.161.pp.293-301 https://doi.org/10.3940/rina.ijme.2019.a3.546

Gambardella, M., Rizolli, A., \& Zaffolan, M., (1998), Simulation and Planning of an Intermodal Container Terminal, Simulation Harbour and Maritime Simulation, 10-98

Holweg, M., \& Miemczyk, J., (2003), Delivering the "3-day car " The Strategic Implications for Automotive Logistics Operations, Journal of Purchasing \& Supply Management ,9, 63-71

Iannone, R., Miranda, S., Prisco, L., Riemma, S., \& Samo, D., (2016), Proposal for a flexible discrete event simulation model for assessing the daily operation decision in a Ro-Ro Terminal,(61),28-46. https://doi.org/10.1016/j.simpat.2015.11.005

Mattfeld, D., \& Kopfer, H.,( 2003), Terminal Operations Management in Vehicle Transsshipment, Transportation Research Part A, 37,435-452

Mangan, J., Lalwani, C., \& Gardner, B., (2002), Modelling port/ ferry choise in Ro-Ro freight transportation, International Journal of Transportation, 1 (1), 15-28

Pau, B., \& Sauri, S., (2005) Performance Indicators for Roll-onRoll-off Terminals: A Planning Assestmnent Tool, Technical University of Catalonia.

Özkan, E., Nas, S., \& Güler, N., (2016), Capacity Analiysis of Ro Ro Terminals by Using Simulation Modeling Method, The Asian Journal of Shipping and Logistics, 32(3), 139-147, https://doi.org/10.1016/j.ajsl.2016.09.002

Şahin,Y.B., Ekmekçi, S.\& Yürekli,M. (2020).Bir makine Fabrikasında Yarı Mamul Depolama Sistemi için Etkin Raf Yerleşimi Önerisi. Avrupa Bilim ve Teknoloji Dergisi (18), 664-674

Yalçıner, A.Y.\& Can,B. (2019).Tam Sayılı Programlama ve Simülasyon ile Raf Alanı Optimizasyonu: Bir Ambalaj Firmasında Uygulama. Avrupa Bilim ve Teknoloji Dergisi (Özel Sayı ), 375-388 